\title{
LAW, ECONOMICS \\ AND THE INSTITUTIONAL APPROACH TO DEVELOPMENT AND TRANSITION: TOWARDS AN EVOLUTIONARY PERSPECTIVE
}

\author{
ENRICO COLOMBATTO*
}

Resumen: Los principios que subyacen a la psicología evolutiva, sugieren una aproximación al Derecho y a la Economía que tiende a rechazar una gestión política de arriba a abajo, y estimula una estrategia de abajo hacia arriba, por medio de la cual las reglas conducen a rutinas de comportamiento que son consistentes con los patrones psicológicos compartidos de los individuos. El enfoque propuesto en este trabajo es fructífero desde una perspectiva metodológica, en el sentido de que permite una nueva clasificación de las sociedades, una nueva visión de sus perspectivas de crecimiento económico, una apreciación innovadora de las oportunidades de transición exitosas en áreas que han experimentado una transformación política sustancial.

Palabras clave: Instituciones, patrones de comportamiento, Derecho y Economía.

Abstract: The principles underlying evolutionary psychology suggest an approach to Law and Economics that tends to reject top-down policy making and encourages a bottom-up stance, whereby rules lead to behavioral routines that are consistent with individuals' shared psychological patterns. The view proposed here is fruitful from a methodological perspective, in that it allows a new classification of societies, new insight on their prospects for economic growth, an innovative appreciation of the chances for successful transition in areas that have undergone substantial political transformation.

Key words: Institutions, behavioral patterns, law and economics.

Clasificación JEL: K00, B52.

${ }^{*}$ ) Professor of Economics at the University of Turin, Director of ICER and Fellow at the «Collegio Carlo Alberto Foundation». I am very grateful to Simon Teitel for his useful comments on a preliminary draft of this work. Previous versions of this paper were presented at the New York Law School's Center for International Law and at the Prague Conference on Political Economy. 
I.

\section{ORTHODOX LAW AND ECONOMICS AND ITS INADEQUACIES}

Most economists outside the neoclassical tradition have always been aware of the importance of the interaction between legal structures and economic behavior (Sima, 2004). Consensus has further widened during the last decade, as an increasingly large number of mainstream scholars have recognized the need to take rule-making into account, either as a component of their models or as a constraint to be dealt with before models are designed and/or tested. In the end, two different approaches have emerged within the realm of economic analysis. One has tended to explain individual behavior as the result of the existing rules of the game or as the effort to alter or preserve such rules, following personal or group interests. The other has emphasized the study of the mechanisms through which given sets of formal and informal rules - traditions, conventions, norms, laws - affect transactions costs, and thus enhance or stifle desirable cooperation among individuals. The former is known as institutional economics, the latter as 'law and economics' (L\&E) ${ }^{1}$.

Surely, the border between institutional economics and L\&E is not always clear-cut, and one might rightly argue that the rules according to which individuals behave are themselves the result of human action. Still, since the 1930s institutional economics and L\&E have developed along somewhat

1 The legal tradition tends to emphasize other aspects, such as the consequences of judicial decisions with respect to efficiency and fairness. Put differently, whereas economists view law and economics as a means to understand people's behavior, lawyers are inclined to consider this discipline as a tool that enables them to better appreciate the meaning and consequences of law making. See in particular Medema (2005) for an in-depth discussion on the economic and legal approaches, which also reflects the debate between the old and the new L\&E schools. 
independent tracks. Institutional economics has emphasized the economics of culture and of rent seeking. It has generated important descriptive and explanatory results, but rather modest normative recipes.

On the other hand, L\&E has often taken the nature and goals of economic activity for granted; and focused on how to achieve such goals by defining and managing property rights. Its normative implications have been of consequence, even if at odds with the praxeological foundations of a free-market system $^{2}$. In fact, traditional L\&E owes much of its success to its rigorous explanations of bad economic performance, even when apparently good textbooks recipes are applied. In particular, the L\&E solution tends to be presented as a package shaped around three pillars. First, success obtains only when the rule-of-law is enforced by a group of Hayekian legislators ${ }^{3}$ supported by an efficient and committed state bureaucracy. Second, independent and omniscient judiciary bodies are to watch over and solve alleged market failures ${ }^{4}$, possibly through a number of state organizations reproduced after neoclassical blueprints. Finally, the L\&E approach would offer valuable guidelines to modify property-right assignments,

2 See Block (1977) for the 'immoral implications Demsetz draws from Coases's view of property'. Indeed, the recent constructivist developments in L\&E have frequently departed from the principles of its forerunners, who were closer to the late nineteenth-century and early twentieth-century reactions to legal formalism (Medema 2005).

${ }^{3}$ Following Hayek (1960), a fair political system attributes a large role to state action, which protects individual freedom, but also provides for a large number of goods and services. Legal scholars and/or philosophical scientists would take care of law making, so as to evaluate and restrain abuses by the state and monitor infringements on individual liberty.

4 As argued in Nicita and Pagano (2007), the mainstream 'approach had an unCoasean flavour. The Nirvana hypothesis had not been removed, but simply shifted from market to judges and this contradicted the Coasean insight that all institutions were costly and no institutional Nirvana existed'. This applies to Posner, who undertakes to maximize social wealth - whatever that means; and to Demsetz, who aims at minimizing transactions costs. 
either according to Chicago-style criteria, so as to approximate the outcome one would have observed in a world with zero transactions costs; or to Yale-style principles, whereby some notion of social fairness is also complied with.

Not surprisingly, L\&E became a much welcome complement to mainstream normative economics. It took care of transactions costs, a well-known soft spot of orthodox textbooks dealing with policy-making. At the same time, it suited the understandable desire to shape an ideal situation where income growth was assured by well-regulated market transactions. Thus, it encouraged much of the profession to believe in the inevitability of growth and development for those countries equipped with the rules and agencies suitable to attract new and significant amounts of fixed capital and to absorb outside technologies.

A substantial body of literature has now emphasized that the traditional L\&E recipe suffers from a number of important weaknesses. From a methodological viewpoint, it relies heavily on the (im)possibility of assessing and measuring individual preferences, without which modifying property rights would make little sense. Furthermore, it assumes that suitable contracts always take place and that when they don't, exceedingly high transactions costs are the explanation. Indeed, there is plenty of evidence that this hypothesis is far stretched. On the one hand the preferences of the potential sellers often differ from those of the potential buyers ${ }^{5}$. On the other it tends to belittle the most important transactions costs, which consists of a biased and inefficient judiciary system (Opper, 2005): training the judges

\footnotetext{
${ }^{5}$ See for instance Block (1977). That also applies to goods that do not generate immediate streams of utility. The economic literature has frequently referred to the fact that agents often choose different means to pursue the same ends as a proof of 'irrationality'. More aptly, Nussbaum (1997) has pointed out that these puzzles are generated by the poor mainstream definition of individual preferences, which omits to mention emotional components.
} 
may help, but is only part of the solution. From a substantive viewpoint, by applying L\&E procedures the judge or the legislator can merely replace the agents' preferences with his own assessment of their preferences. Or disregard their preferences altogether and replace them with his own, which are necessarily arbitrary, even when the legislators' personal or group interests are heroically assumed away ${ }^{6}$.

Either way, in this context the foundations of the judge's action do not seem beyond dispute. The moral ground that justifies the overruling of individual preferences is shaky, for it is hard to conceive an acceptable criterion through which preferences can be ranked across individuals. In addition, lawmakers hardly ever operate in a vacuum when they define and assign property rights. Should goods be available because nobody previously thought they were of any use, then the rule of the first occupant/user applies. Neither L\&E prescriptions, nor judges have much to add. On the other hand, goods that cannot be accessed or used without aggressing a counterpart reflect a situation where somebody else de facto owns them. Hence, all normative prescriptions designed to enhance an optimal allocation of rights - whatever that may mean - are in fact a violation of property rights, unless such prescriptions replicate the outcome of the existing contractual agreements ${ }^{7}$.

\footnotetext{
6 See for instance Bernstein (2005, pp. 109-112).

7 Parisi and Klick (2003) make the case for a functionalist version of law and economics. They attempt to reconcile L\&E with a free-market perspective by recommending general rules so as 'to induce individuals to internalize the effects of their private activities, as well as [...] to reveal their true preferences in situations where collective decisions must be made' (p.2).
} 
II.

\section{THE BEHAVIORAL ALTERNATIVE}

The behavioral approach offers a different perspective on norms and economic action by focusing on individual choices, rather than outcomes ${ }^{8}$. As a consequence, it avoids all assumptions about rationality, a crucial weakness of the neoclassical vision of law and economics. Instead, it takes into account 'bounded rationality, bounded willpower and bounded self-interest' (Jolls, Sunstein and Thaler 1998, p.1476) and acknowledges that altruism, Mandevillian sociability, envy and fairness, pride, also characterize individuals' preferences. Thus, decisionmaking routines serve the purpose of reducing information costs, uncertainty and thinking time. Put differently, behavioral law and economics does not aim at producing rules and legitimizing assignments or procedures that lead to some kind of efficiency determined in terms of income streams. Rather, it insists on formulating rules that are desirable because they stem from evolution by natural selection (Jones, 2000) ${ }^{9}$, are consistent with the shared values of a community and allow for differences in personal ethical standards. Of course, this begs two important questions.

First, one should identify the role of the individual with respect to the community. For instance, in a free society the

8 The functional approach also claims to be concerned with efficient procedures, rather than outcomes. This claim is not fully persuasive, though. In fact, two possibilities may occur. Either the quality of a procedure is assessed according to the features of the outcome it leads to. If so, the emphasis on procedures is fictitious and the difference between the orthodox and the functional view becomes rather thin. Or the quality of the procedure is judged according to the institutional environment within which individuals choose. If so, functional Law and Economics would be the normative side of the new institutional economics.

9 Of course, "This is not at all the same thing as claiming (as some critics incorrectly presume that those who invoke biology automatically claim) that all biological predispositions are fortunate, simply because they have evolved'. (Jones 2000, p. 2088). 
individual has a right to exemptions whenever a rule interferes with his/her personal liberty (the freedom from coercion). But in most social frameworks the rules of the game are different from those of a free society, and one has to assess when opting out is permitted. Second, people's preferences often display changes in needs and perceptions, which are sometimes described as behavioral inconsistencies and possibly lead to extreme conclusions: Either rules are changed and re-assessed on a daily basis in order to take into account all these changes; or rules are just a short list of principles, broad enough not to be changed for long periods of time and precise enough not to allow those in charge of enforcing them to exercise any discretionary power ${ }^{10}$.

III.

\section{THE PURPOSE OF LAW AND ECONOMICS REASSESSED}

The contrast between the orthodox and the behavioral approaches is surely important from a positive standpoint, since it highlights the need to take into account 'irrational human behavior' when trying to understand social phenomena. Of course, that also affects the evaluation of rules, since the way people react to the incentive systems defined by rules depends on the features of each individual.

Put differently, mainstream L\&E starts out by defining a measurable goal (achieving allocation efficiency, minimizing criminal behavior, attaining fair distribution of income) and analyses the most suitable way to modify and enforce either property rights or rules in order to obtain predefined objectives.

10 That might contribute to explaining why bad legislation abounds in societies that do not operate according to natural law, but to a historicist approach. Politicians necessarily follow the whims of the public they represent. And they also take advantage of short-lived emotions to advance rent-seekers' interests. 
Not surprisingly, preferences and persistent behaviour are considered as one (Stigler and Becker, 1977): that is, preferences are assumed to be constant and human behaviour to reflect the most efficient way to satisfy given and stable preferences. In the end policy action is justified as long as it reduces alleged market failures. Preferences can actually be ignored altogether (Stigler and Becker 1977), for apparent differences are just the product of different incentive systems, which in turn are determined by property rights and transaction costs ${ }^{11}$.

On the other hand, the behavioural perspective relies heavily on evolutionary psychology, which suggests a much more cautious view towards policy-making and the evaluation of results. It claims that behavioral routines follow from psychological patterns that evolve through century-long experiences and trial and error processes. Contrary to the standard L\&E view, patterns are not constant and routines do not depend on transaction costs only. Instead, the origin of their differences is historical (culture) ${ }^{12}$, rather than technocratic. More precisely, individuals are not machines that come to life and follow their pre-programmed instructions in spite of the environmental conditions, as most cognitive psychologists tend to assume. Nor are they blocs of clay moulded by the external conditions, as the radical-behavioural school would argue. Instead, according to the evolutionary approach, human behaviour is the outcome of a lengthy process of adaptation, a frame of mind that turned out to be suitable to solve or avoid a problem. The analysis of the interaction between the way we are and the stimuli we are

${ }^{11}$ Hence, the ethics of policy making orbits about the dynamics of transaction costs. The way to historicism is wide-open once again.

12 See for instance Hofstede (1991 [2003]), who classifies different cultural patterns according to four parameters and provides empirical evidence. Quite rightly, Hofstede makes a distinction between culture (also defined as the software of the mind), which is acquired in early age; and human nature, which is genetically inherited. This article refers to both at the sane time by referring to "psychologically patterns», which therefore include both inherited traits and young-age learning. 
exposed to is thus key to understanding human action and society (see for instance Buss 2004). When mutually compatible, routines consolidate in social norms, informal rules. Indeed, social interaction is framed by such informal norms (Ellickson 1991). Formal rules are necessary only when informal conventions are misunderstood, or when they break down; and when the system of sanctions typical of the informal code turns out to be inadequate. As a result, three sets of arguments are put forward from a behavioral standpoint.

First, law-making should be restricted to filling the gaps of spontaneous social interaction. For instance, that applies to the definition of sanctions, especially when transactions involve agents who do not belong to the same (relatively small) community. Or to default rules when the interpretation of the contractual agreement turns out to be questionable, especially in cases where the pertinent informal rule is far from certain or consolidated in common use. This was indeed the historical role of Common Law, as argued in Zywicki (2003, p.1622). Second, law-making could be welcome in the presence of imperfect behavioral updating. As already observed by Hayek (1960 [1978, p.286] and 1973 [1983, pp.88-89]) when advocating active rule-making, behavioral patterns evolve gradually, definitely slower than the environment within which individuals operate, both from a technological and an institutional viewpoint ${ }^{13}$. As a consequence, routines might become outdated quickly. The actions that follow from such obsolete routines may no longer be appropriate to meet current preferences. If so, law-making could then anticipate behavioral evolution, provided - surely a strong assumption - that the law-makers are equipped with prophetic abilities or characterized by

13 Globalization is a prime example in this context, as it includes a dramatic fall in transportation and communication costs, as well as in tariff and non-tariff barriers. 
relatively fast evolutionary patterns that are known to anticipate general behavior. Finally, there remains room for legal innovation, too. New routines do not necessarily come to the surface by chance. And they are all the time enhanced by new ideas, proposals, contractual varieties. Thus, experimental lawmaking should be prominent and always allow for some kind of opting-out, so that (natural) selection one of the pillars of the evolutionary approach can take place.

All that of course assumes that policy-making is indeed legitimate. That is not warranted, though. For the behavioral standpoint shows that if one accepts that formal norms must serve social interaction, and that the individuals belong to a society for geo-political reasons ${ }^{14}$, other questions deserve to be answered even before policies become an option. As global interaction intensifies and local communities grow to be increasingly porous - possibly falling apart altogether it becomes rather difficult to maintain that a group of individuals share the same objectives or the same psychological patterns just because they share the same capital city. Put differently, it might not be easy to define social objectives or social behavior. Still, they are the very notions that L\&E should address ${ }^{15}$.

\footnotetext{
14 In this case the notion of a 'society' coincides with that of a 'country'. This is the area where a formal institutional framework (a set codified of laws) applies.

15 The logical problem can be presented as follows. Small communities with strict internal behavioral codes may be thought to represent an ideal society for the purpose of law and economics: shared objectives and shared behavioral evolution. But at the same time they present little scope for any L\&E intervention, since within this framework informal rules would prevail and actually satisfy all the normative needs. On the other hand, in larger and more open societies coordination problems may be more serious and difficult to solve. Then, the very notion of society loses its original meaning. As a consequence coercive interference loses legitimacy, too.
} 
IV.

FROM LAW AND ECONOMICS TO DEVELOPMENT AND TRANSITION

In the previous paragraphs it has been claimed that L\&E offers rather questionable guidelines for policy-making. By and large the argument is negative, i.e. normative action would violate individual preferences and be arbitrary. In the end it reveals teleological ambitions without sound criteria to single out an objective. The practical consequences can be detected in the so-called transition and developing countries, where the old norms have broken down or are deemed less than appropriate, and new norms seem to be in demand.

If culture matters and violent shocks like wars or revolutions are ignored, rules usually change over long periods of time they are indeed evolutionary phenomena that follow a process similar to natural selection. New rules of the game will come to the surface gradually, as the old ones become obsolete. Surely, from a cultural viewpoint there is little or no need for L\&E intervention. In other cases, however, change is rapid, for instance when the old formal rules are invalidated in the aftermath of a political crisis - say, when a dictator loses power or a regime collapses. Even in this case, however, L\&E can be disappointing, for one can hardly know where a society is heading or, more aptly, which new behavioral routines are going to replace the old ones. For sure, and contrary to much policy advice coming from all directions, if one believes that psychological patterns are a cumulative process whereby today's blueprints are somehow dependent on yesterday's guidelines, developing and transition societies will never reproduce the Western model, unless in the very long run and under rather restrictive hypotheses. At most one can hope that foreign institutions be imported, modified, adapted and harmonized with the existing rules of the game: outright 
substitution would be a recipe for failure (Sachs et al., 2000; Berkowitz et al., 2003).

There are even reasons to believe that in some cases transition and development processes should be left in the hands of at least some among those who operated the old system. This applies when the old system has been in place long enough to generate behavioral routines that have been absorbed into psychological patterns, thereby leading to path-dependence and inertia ${ }^{16}$. Under such circumstances, the existing psychological patterns do not necessarly disappear overnight when the old political system breaks down. On the contrary, they often remain in place and change very slowly through repeated interaction, towards good or bad outcomes. If so, the new routines to be enforced are successful only if they can build on the incumbent psychological patterns.

In practice, it is here argued that the pace of evolution can accelerate and be consciously driven towards given goals only if the authorities can provide credible commitments based on their understanding and personal records of social interaction and can offer expected responses to people's actions. Agents that operate in a new political context are encouraged to be consistent and consolidate new psychological patterns only if they know who their counterparts are, are familiar with their conduct and know that their counterparts know them.

On the contrary, top-down institution building can certainly lead to radical changes in behavioral routines. But it hardly modifies psychological patterns. Different outcomes can materialize, as will be discussed more carefully later. It is however already clear that from this perspective even the ideal

${ }^{16}$ One may thus imagine to classify transition/developing economies according to the combination of their behavioral routines and their psychological patterns. The outcome of these combinations determines their chances to obtain fast institutional change. This approach may indeed explain the different reactions to political change in various parts of the developing world. 
textbook situation is intrinsically inconsistent and bound to fail. For when allegedly-efficient assignments of property rights break down current behavioral routines, they destroy the potential reference points for the evolving psychological patterns. As a consequence, either the old patterns are strengthened for lack of affordable substitute compass reading; and new routines develop as a compromise between the efficient rules and the 'inefficient' patterns. Or the allegedly efficient new routines are ignored altogether and the existing behavioral practices are left intact (Rapaczynski, 1996). This may help understand why the same L\&E prescription were expected to generate similar results and in fact gave origin to all sorts of different responses.

$\mathrm{V}$.

\section{THE INSTITUTIONAL ALTERNATIVES}

The above also applies to the normative legacy of the (new) institutional economics, which maintains that institution building is a necessary requirement for successful economic performance, but neglects to emphasize that it has never been sufficient: In some cases the incumbent elites successfully resist pressure to reshape the institutional context, least they might lose their privileges and control of power. In other cases the new rules and agencies are misused or simply disregarded. For instance, substantial parts of the former Soviet bloc and of SubSaharan Africa abound with brand new Stock Exchanges with little or no stocks to trade.

Although the lesson has not been yet been learnt in full - several national and international agencies keep insisting on top-down institutional design and building less technocratic approaches have recently been re-examined in a more favorable light. The basic ideas have been borrowed from the old institutional school (OIE). In particular, social interaction is 
now understood to be the result of extended trial-and-error processes through which individuals learn how to improve their well being. Similarly, it is acknowledged that change does take place following environmental and technological conditions. But it is equally recognized that it is slow and based upon past experience, the teachings of which are absorbed gradually, as the new behavioural routines turn out to be preferable to the old ones and create novel modes of interaction.

This approach to slow evolution has emphasised the need for consistency between codified and implicit norms, i.e. formal and informal rules, according to the current terminology (North 1990; Pejovich 1999). Ideally, formal rules should be shaped and dictated by informal rules, which serve the purpose of enhancing information and reducing transactions costs generated by cheating, opportunism and the need for ex post evaluation. When this does not happen, tensions create room for discretionary power by lawmakers and law enforcers, raise the transactions costs for the agents, lead to problems of credibility and thus reliability of the exchange system and eventually to poor economic performance.

One may thus conclude with the (old) institutional view that an acceptable legal structure must be consistent with the cultural background of a society. In particular, the less evident the cultural traits of a community, the less binding the rules should be and substantial opting-out possibilities should be available. For instance, contract law (including the system of sanctions regarding breach of contract) should then be subject to competitive judiciary systems, whereas torts and criminal law should be subject to path dependence (precedent). 
VI.

TOWARDS AN ENRICHED

CULTURAL APPROACH

The Old Institutional approach ${ }^{17}$ is of course convincing, in that it is diffucult to claim that rules should go against shared moral standards filtered through decades if not centuries of social interactions. Even when behavior does not seem to generate satisfactory performances, efficiency per se provides little legitimacy to violate individual freedom and force agents to accept other behavioral patterns. Following Leoni (1961 [1991]), law-making - changing the way human beings behave towards desirable patterns - should then be replaced by efforts to find out how people intend to behave (law as a discovery process). Hence the role attributed by natural-rights scholars to information, trial and error processes, history, traditions.

Still, the problem with the old institutional economics is that it is a description, rather than an explanation of human behavior. At best it depicts how behavior evolves when existing routines are confronted with new technological opportunities or new historical contexts, whereby path dependence (inertia) breaks down and new ways to interact appear possibly new organizations, too. In particular, two processes can be observed. Either the new cultural pattern is molded through a competitive process, so that selection favors the most desirable solutions, i.e. those that enhance exchange and the acquisition of knowledge. Or the old and new rent-seeking groups cooperate and strive to preserve or strengthen their rents. As the literature has emphasized, sometimes the former prevails, sometimes the latter. Much depends on geography, historical accident, ideology.

Put differently, one cannot escape the impression that in the end the explanatory element of the cultural view is either

17 Unless specified, the terms 'old-institutional' and 'cultural' are considered synonymous. 
residual or tautological. For when human behavior is not 'rational' or 'bounded-rational' in the neoclassical sense, then systematic deviations necessarily come from tradition (including prejudice) and personal preferences - i.e. culture broadly speaking ${ }^{18}$. Similarly, saying that economic performance is below expectations because desirable institutional frameworks fail to be operational (or don't exist) is equivalent to saying that violence or tensions between formal and informal rules dominate ${ }^{19}$. Among other things, this would not be too far away from the argument made within the traditional L\&E and the neoinstitutional fields, according to which there is a case for advocating more effective law-enforcement and perhaps policies designed to enhance some kind of cultural catch-up. The debate on shock therapy and gradualism in transition countries can actually be framed in these terms, whereby the former view emphasizes credibility, the latter cultural change. In the end what matters are not only the features of the new pattern, but also the capacity to accept and act according to the new patterns. This indeed is the lesson taught by successful slow and fast privatizers in Eastern Europe (quoted in Opper 2005).

However, the picture may acquire a new shape if the notion of culture is analyzed in behavioral terms, that is if one takes into account the fact that individual 'behavior flows from brains that (a) encounter specific environmental stimuli and (b) possess a neural architecture that is as importantly shaped by environments as it is by genes' (Jones and Goldsmith 2005, p. 428). Although still developing ${ }^{20}$, this conceptual frame shares

18 Emotions are outside the cultural view, for they are short-lived by definition. When they are systematic, they become part of the culture.

19 As aired earlier on, these tensions weaken the reliability of the whole rule system, with a negative effect on growth.

20 Once one upholds that emotions, ideologies, external environments dominate behavior, then one needs a theory in order to explain endogenous behavioral patterns. Unfortunately, the behavioral school is still lacking in this respect. A possible alternative is Jacques Lacan's theorizing of irrational behavior (see 
the OIE view whereby a society develops and prospers when individual behavioral routines are compatible and to some extent mutually expected, either because agreed upon in advance (say, by means of a contract) or because implicit (shared values, informal rules). But it also adds that the relevant shocks are those experienced when rapid changes in behavior come about, either because psychological patterns evolve quickly, or because those behavioral routines that were imposed on a given psychological pattern are being removed before the underlying patterns undergo significant change. When this occur, the new behavioral routines develop along with some elements of the superseded routines, and by interacting with the existing patterns.

More generally, a set of shared principles and behavioral routines (tradition and habits) acquire different meanings according to the genetic traits - the psychological patterns they reflect. For instance, a society where genetic traits have developed as a consequence of the adoption of exogenous behavioral routines for a long enough time is likely to exhibit different features when compared with a society where routines have developed from say spontaneous interaction among free individuals ${ }^{21}$. In this light, the term culture acquires different meanings - depending on whether it reflects behavioral

Schroeder 2000 for a discussion of Lacan's view within law and economics). Lacan's approach is also consistent with the notion of stable tastes put forward by Stigler and Becker (1977). Still, Lacan's vision seems more apt to explain individual reactions to the outside world, rather than the development of what D. North would call 'belief systems'. This is probably due to the fact that in Lacan's world there are no belief systems altogether, but only 'desires' (pursuing a goal such as satisfaction or morality) and 'drives' (hedonism).

21 One can oppose the case of France (and large areas of continental Europe) to that of England (and the Anglo Saxon world). In both cases the notion of the nation state developed as from the late 17 th century and became an important reference point for the individual. However, in the first case the state was to achieve what the individual could not obtain all alone - including some arbitrary notion of the collective good, be it collective security or aggressive capabilities. Whereas in the second case the state was justified in that it protected individual liberties. 
routines or psychological patterns ${ }^{22}$. In short, the term 'culture' lacks power as an operational device. As argued above, the concepts of behavioral routines and psychological patterns seem to be more useful in that they are able to include a wider variety of situations, including those under the remaining headings - non-development, oppression and transition.

VII.

\section{THE EVOLUTIONARY NOTION IN PRACTICE}

Once the old institutional view is enriched through the behavioral elements outlined above, economic development can be appreciated in a new light. This paper considers four categories of situations - developed, undeveloped, oppressed and in transition.

\section{Developed countries}

A developed country is here defined as one where behavioral routines are consistent with the agents' psychological patterns (which include preferences as well as spontaneous reaction vis$\grave{a}$-vis external stimuli). GDP levels are thus irrelevant. In other words, development obtains when the principles underlying the

22 One of the ambiguities is related to the notion of 'heterogeneous cultures', which is widely accepted by anthropologists, but inevitably creates problems to the economists, who tend to refer to culture in order to define a common system of values (or belief systems, as they are sometimes called). From the analytical standpoint suggested here the quandary could be solved by observing that heterogeneity refers to the presence of different psychological patterns, which may nevertheless lead to shared behavioral routines, that is tolerable reactions to given outside stimuli. For instance, most members of a society may not approve cheating, but cheating can still be tolerated if it is widely acknowledged that the victim is unworthy of a better attitude. The fragility of these cultural systems is then explained by the changes in the exogenous incentives, which leave the psychological patterns unchanged, but may modify the routines. 
prevailing rules of the game are widely accepted. In developed countries these principles or moral standards are embedded in the observable behavioral routines and there is no need to reach a compromise between morality and psychological patterns. Tensions, if any, concern the intensity and consistency with which such criteria are applied. They inevitably turn out to be a question of too much or too little redistribution.

This has a number of implications worthy of notice. First, in developed economies the role of the distinction between formal and informal rules weakens. Following our definition a developed country can have formal rules that are indeed inconsistent with the informal norms. But the very fact that behavioral routines are well supported by the psychological patterns implies that formal rules are simply ignored and/or considered as an additional transaction cost to reckon with ${ }^{23}$. Second, the very notion of informal rules becomes less important, for it can apply to different situations. For instance, informal rules do develop spontaneously as a result of repeated interaction among agents exchanging goods and services and, more generally, acknowledging and enforcing property rights. But they can also come to the surface as a reaction to distorted institutional situations - say, a totalitarian regime and yet run against the current prevailing psychological patterns. That is what happens when we compromise. It then follows that the nature of informal rules does not say much about individuals' preferences and that inconsistencies between formal and informal rules can be ascribed to different categories of situations, depending on whether informal rules are the result of shared behavioral routines or not.

23 For instance, this applies to countries where the so-called underground economy is a substantial share of production, as in many European regions. As mentioned in the text, a country is developed if there are no tensions between behavioral routines and psychological routines. This does not rule out that formal and informal rule differ. But it rules out that such differences generate serious tensions. 


\section{Undeveloped countries}

According to our analytical framework, in undeveloped countries psychological patterns are well adapted to the existing behavioral routines. These, however, are less than satisfactory, especially as regards economic performance. Still, under these circumstances individuals are unwilling to introduce new incentive systems or change the traditional response to the existing institutional stimuli. Put differently, the origin of dissatisfaction is not the violation of relative preferences, but simple envy (absolute preferences) ${ }^{24}$. Thus, in these cases the concept of backwardness involves perception, rather than some measure of the living standard. Agents operating in 'backward societies' do perceive that they are producing well inside the production possibility frontier, but are unwilling to take the necessary steps in the required direction. In other words, the so-called poverty trap stems from inefficient behavioural routines which are however consistent with the software of the mind.

This allows to conclude that backwardness is a relative notion. No undeveloped country would consider itself poor or disgraced unless its residents could compare their living standards with those of other countries ${ }^{25}$. Should dissatisfaction be an absolute notion, it would be generated by either undesirable behavioral routines, or evolving genetic patterns. If

${ }^{24}$ Absolute preferences refer to what people would like to have and with what intensity (e.g. more holidays or a better car). Of course, the intensity of our desires depends on how realistic they are and on how much satisfaction the desired goods and services are expected to provide. Instead, relative preferences are related to choice, i.e. they depend on being aware that choosing to consume one unit of $X$ today implies giving up some amount of $Y$, today or in the future.

25 This view is confirmed if one compares some rich Western countries in the XIX century with some of today's countries with similar GDP per-capita. GDP per-capita in the Netherlands in 1820 was about 1,550 dollars (at 1990 constant prices). Still the Dutch considered themselves rich, whereas today's Egyptians and Pakistanis (with some 1,900 and 1,650 dollars per head in 1992, respectively) are considered poor. 
that were the case, however, the country would fall in the 'oppressed' category, to be explained below.

As regards economic performance, backwardness has no easy solution, for it does not present a real problem to begin with. The consistency between behavioral routines and psychological patterns demonstrates that the existing situation may not be considered attractive by those living in developed societies. Nevertheless, it turns out to be in step with the preferences of most agents living in that (undeveloped) community ${ }^{26}$. This contributes to explaining the persistence of poverty as well as of actual or potential political instability in undeveloped countries ${ }^{27}$. But contrary to what is commonly maintained, poverty is generated by the impossibility and even the unsuitability of reforms designed to introduce new behavioral routines.

\section{Oppressed countries}

The case examined above constrasts with what is observed in oppressed countries, where behavioural routines are the results of psychological patterns filtered through exogenous constraints.

${ }^{26}$ A testable experiment is the observation of migrants to developed countries. Resistance to accept the routines prevailing in the new country reveals unchanging habits, i.e. persisting genetic architecture geared to the rules of the game prevailing in the (backward) country of origin. Then, difficulties in integration and repeated attempts to game the system (possibly through crime) should be correlated with the undeveloped nature of the country of origin.

27 In particular, political instability has two sources. One is related to the exploitation of envy by political competitors. For the reasons explained in the text, incumbent politicians are unlikely to enact policies that make higher living standards possible. If they did, they would be voted out systematically. The lack of action by incumbents combined with envy leads to frequent changes of leadership. On the other hand, incumbents may choose to establish a totalitarian regime, which can survive by creating rent-seeking practices to the benefit of ethnic or family supporters. In turn, the accumulation of substantial rents creates incentives to stage a coup. In this case the regime remains the same (totalitarianism), but the ruling elite is replaced. 
Put differently, in this context individuals are prevented from pursuing their own preferences by more or less systematic violations of their freedom. Therefore, they adapt to the external constraints. Adaptation can of course generate different behavioural routines, following the nature of the agents. For instance, some might try to abandon the exploited groups and join or collude with the winning rent-seekers (the 'oppressors'). Others might choose to form new coalitions with the purpose of ousting the incumbents, either to replace them or to carry out deep institutional change ${ }^{28}$. The majority probably just gives in, and tries to carry out small-scale rent-seeeking; or dodge the system by diving into the so-called informal sector; or cheat and take as many free rides as possible.

Not surprisingly, who does what depends on a variety of variables that reflect individual propensities - e.g. risk aversion, entrepreneurial spirits, ambition - rather than moral standards. That explains why in oppressed countries there appear different behavioral routines, even if the formal rules of the game and the psychological patterns are the same ${ }^{29}$. Clearly, oppressed countries can be high- or low-income economies, depending upon the moment in history when oppression is introduced. They can be growing or stagnating, following how oppression affects entrepreneurship and exchange; and be characterized by both stable and unstable political systems, as a result of the prevailing attitudes, perceptions, ability of the rent-seeking coalitions to secure power through the exercise of violence.

28 The first case is the 'palace coup', not unlike what happens in undeveloped countries. While the latter is a change of regime - say, from dictatorship to democracy.

${ }^{29}$ Once again, culture refers to the existence of common psychological patterns. But these may stay alive with - and originate - different behavioral routines, either because of distinct incentives systems (normally across countries), or because of different individual features (personalities). 


\section{Transition}

Finally, a situation of transition occurs when (i) psychological patterns are no longer consistent with the external environment and (ii) individuals agree on common behavioural routines that either make the existing formal environment irrelevant, or are judged adequate to justify and obtain environmental change. That applies of course to the recent experience of some countries in Central and Eastern Europe, where transition has been considered a desirable phenomenon. But it also pertains to less desirable contexts, such as - for instance - the transition from the Weimar Republic to Nazi Germany. And can also give way to rather confused situations, say when the ex ante consensus on the new beahvioral routines (e.g. capitalism) turns out to be an exercise in wishful thinking.

VIII.

EXPLANATION AND PREDICTION THROUGH THE EXTENDED INSTITUTIONAL APPROACH. TWO EXAMPLES

\section{Developed economies and the welfare state}

A developed country has been defined as one where behavioral routines are consistent with the agents' psychological patterns. There is no 'moral problem'; and dissatisfaction relates more to the distribution of income within the community or the country, rather than to overall income and wealth. In other words, within this context envy targets other individuals within the country, not other systems. Let us now apply this notion to formulate conjectures about the future of state intervention in the EU area.

Mainstream law and economics offers a straightforward solution. As long as it is apparent that the state production of 
private goods is inefficient ${ }^{30}$, state intervention must be reformed following a relatively simple process. Property rights should be transferred to private producers in order to maximize efficiency. Some (regulatory) rights would nevertheless retained by public authorities in order to compensate for the so-called 'market failures'. Further rights to people's income and/or wealth would be handed out to the state authorities in order to enact redistribution and maximize a previously defined social welfare function.

As argued in earlier, the alternative focuses on behavioral routines, which in this case consist of the agents' revealed attitudes towards political and bureaucratic intervention. Although generalizations are always dangerous, an evolutionary approach suggests that state interference is perceived in two different ways. On the one hand there exist developed EU countries - like Denmark or Finland - where the interaction between the state as a producer and a redistributor on the one hand, and the individual on the other, is cooperative rather than conflicting. When this applies, the state is acknowledged to meet the need for collective insurance against - say illness, unemployment, old age, education. These needs are clearly perceived and widely shared to more or less the same degree by these populations. No value judgment comes into the picture, and the state meets such need as if it were some sort of expansion of what already experienced at a local-community level. Free riding by the consumers (say, unjustified consumption of public health services) or by producers (shirking or corruption by state employees) is minimized by deeply rooted and self-

30 By and large, inefficient production has three different explanations. First, elected politicians and lifetime state employees are only loosely responsible to residual claimants and thus present weaker incentives to perform and satisfy demand. Second, in the public sector the residual claimant is the taxpayer, against whom violence can be applied legally. Finally, state producers can often enhance their market power by restricting entry, so that rents are created and maintained. 
reinforcing moral standards ${ }^{31}$, which frequently translate into collective monitoring and lead to moral sanctions (shame) for those who misbehave. Thus, in this category of situations the favorable attitude to the welfare state stems from psychological patterns that originate from the deliberate search for collective solutions to individual problems. They are deeply rooted in collective moral standards: and therefore the ensuing behavioral routines are widely legitimized.

On the other hand, in most other areas of Continental Europe, more or less large groups of citizens might profit from state intervention and welfare-state action ${ }^{32}$. In all such cases the state is then considered as an opportunity by means of which one can exploit others. And it is therefore welcome. At the same time, however, it is regarded as an intruder and a potential

31 Self-reinforcing through state education, which underlines the sense of national belonging and the need to preserve social cohesion at a local and national level.

32 Explaining why this applies in some countries rather than others is beyond the scope of this paper. Three possible avenues of investigation can however be suggested, although none of them will be pursued any further. One regards the role of religious hierarchies. It could be argued that in many European regions religious authorities provided and enforced the behavioral rules that made social interaction possible and sometimes even prosperous. Sanctions were credible, and extended beyond life, if not to eternity. In other areas religious influence was weaker and social interaction had to rely on agree-upon ethical rules monitored by the parties involved and enforced by means of informal rules (including ostracism). When the influence of religion declined, behavioral rules had to be replaced by formal legal arrangements, except for those areas where alternative arrangements were already in place and deeply rooted in individuals. If so, the different psychological approach towards social institutions explains the different way the welfare state is perceived across the various communities.

Other possibilities relate to the way the state is perceived since its role in the so-called Western Civilization began to increase. In many areas the state was the result of foreign occupation or political transformation, as in the case of the French Revolution. In these cases the civil service was considered to be both an intruder and an exploiting agent, either to be resisted or to be fooled; but never to cooperate with. Other circumstances led to a growth of the state as a consequence of conflict, whereby the state rapidly increased in size during wartime, but failed to go back to its previous dimensions afterwards. Once a gain, it emerged as a top-down process often times driven by selected interest groups. 
threat to one's own well-being. As a result, in these countries the attitude towards the state depends on whether one considers himself a winner or a loser - or both at the same time - within the rent-seeking game. Surely, hardly anybody would regard it as an instrument of cooperation in order to attain shared goals.

If the above holds true one may then conclude that the welfare state is a component of a developed economy in a rather limited number of cases. In the majority of situations its presence reveals a status of backwardness, whereby behavioral routines are consistent with psychological patterns, but individual are nevertheless dissatisfied about the outcome. Paradoxically, the inefficient welfare state has little legitimacy, but it is nevetheless accepted, and sometimes actively supported. Indeed, the incentives to reform it are limited. As a result, many so-called advanced countries would be trapped in a state of backwardness featuring a welfare state that is going to be contained for budgetary reasons, but not reduced. Indeed, they would belong to the undeveloped bloc, following our categories.

Surely, there would be little to do, other than identifying those areas of state intervention that might be outside the prevailing patterns, recommend reform so as to reduce abuses, suggest amendments that allow minorities to opt out of taxfinanced programs of government-produced services, or to choose with their feet and migrate towards existing or newlycreated institutional systems that are consistent with psychological patterns usually disregarded in larger jurisdictions. On a grander scale, one could try to alter the prevailing psychological routines. That is where the battle for ideologies plays a key role and what motivates - for instance - think tanks. 


\section{Institution building after communism}

The downfall of communism in Central and Eastern Europe has tempted neoclassical scholars of all trades by giving them the illusion of accessing a green field context where the best possible social rules could be exported and effectively enforced $^{33}$. There was a question of timing, which led to the debate between shock therapy and gradualism. And there was a question of substance, which mainstream L\&E solved by offering instructions to create and assign property rights, subject to efficient regulation and a vaguely-defined welfare state the latter being partially justified by the need to buy consensus from those expected to favor or regret the old regime.

These pages emphasize the need to focus on the nature of the post-Soviet economies before getting dragged into finetuning debates. In particular, it should be observed that some of these countries came from a condition of oppression that evolved into transition as soon as the dictatorship collapsed. Whereas others seemed to feature a condition of backwardness, rather than of transition. If so, the end of communism in the latter group of economies had very little impact on the behavioural routines - including those relevant for economic performance. In these (backward) countries the behavioral routines observed under communism were indeed consistent with the underlying psychological patterns. Individuals were not particularly happy with their own state of affairs. But they had adapted to the existing institutional context, had accepted the operating property-right distribution and were willing to play games with the system in order to maximize their perceived

33 Social scientists frequently devote their skills to such exercises. In recent times constitutional scholars have been drafting perfect rules for countless African and Latin American countries, following the example of Rousseau on Corsica. With very few exceptions, their lack of knowledge about the countries and populations involved never seemed to be a strong enough reason for restraint. 
rents and thus their welfare. In short, their psychological patterns were structured on systematic rent-seeking and refusal of responsibility. Their behavioural routines reflected this broad attitude. Different rules of the game were not only rejected, but hardly conceived.

One suspects that in these cases efforts to introduce capitalism were and are bound to fail, for all the rules that characterise a free-market system are likely to be shaped or turned into rentseeking and rent-sharing opportunities. For example, reputation did matter in the pre-1989 world. But within a competitive system reputation is upheld erga omnes, both inside the outside the group. Instead, within communism interaction is mainly among groups and coalitions, so that reputation matters only within the coalition or when one acts on behalf of the coalition. That explains why the change of political regime hardly mattered (and matters). The state remains a countepart that provides and enforces privileges in exchange for loyalty and/or bribes. Therefore, there is nothing wrong in playing games with it or cheating. Not suprisingly, new constitutional designs are perceived as the foundation of new sets of privileges, rather than as a guardian of the rule of law, competition, individual responsibility. According to Sachs et al. (2000), this is indeed what happened in Russia - but not in China or Vietnam when capitalism was introduced.

Nevertheless, there is still hope for post-communist prosperity in undeveloped countries. Whereas totalitarian regimes made it relatively difficult for residents to interact with foreigners, postSoviet political systems (and communication technology) are relatively open and allow contacts with individuals featuring different psychological patterns, whose behavioural routines are not only sustainable, but also more attractive. Imitation follows and may engender new psychological routines that eventually conflict and/or accelerate behavioural change on a grand scale. When that happens, transition takes off. 
On the other hand, it is here claimed that in those economies that are today regarded as more or less successful transition countries - among which the Baltic republics, Hungary, Slovenia, Poland - individuals during the communist period succeeded in preserving their original patterns. Between the late 1940s and 1989 people adapted to the new political circumstances (oppression) and therefore changed their behavioral routines. But did not find it difficult to revert to more congenial blueprints once communism collapsed. For instance, and contrary to what experienced elsewhere, gaming the communist state yesterday was not the same as cheating the state today. Bribing was once admitted to make oppression bearable; but less so today, when political oppression has been removed.

Of course, this does not necessarily imply that in transition countries individuals are systematically devoted to free-market principles. Indeed, rent-seeking is even openly justified on the basis of nationalistic ideology, much as in the XIXth and XXth centuries. The notion of self-responsibility is also ambiguous and closer to the western-European versions of socialism, rather than to the Anglo-American ideal of freedom. That may shed light on why countries that performed more or less the same under communism - say, Bulgaria and Poland, or Belarus and Estonia, respectively - have been doing very differently in the post-communist period. And also makes it easier to predict the future of the transition countries properly defined, which at the beginning is likely to be consistent with the prevailing psychological patterns transmitted through - and inherited from - the communist period. In particular, these countries may be expected to be heading towards some sort of quasi-liberal society, where various ideologies - be it nationalism, national cohesion or solidarity - persist and justify rents, infringements upon property rights. Growth will remain disappointing, though - at least for a while. But the rise in incomes is likely to gain momentum in the future, as long as the new generations adapt 
the old routines to the new circumstances and are not enticed by the ethics and the illusions of the European superstate that currently seems to seduce so many Westerners.

IX.

\section{CONCLUDING REMARKS}

The undisputed early success of traditional law and economics has several origins. Economists were happy since the various versions of the LEE approach put forward apparently satisfactory explanations to poor economic performance, thereby complementing the contributions offered by the (new) institutional scholars. At the same time, it contributed to filling some of the gaps left open by neoclassical analysis - the role of transactions costs and property-rights allocation and seemed to elaborate an easy way around individual preferences. Law scholars were also happy, since LEE promised to draw a clearcut divide between economic performance and a Rawlsian notion of justice; and at the same time allowed to attain efficient solutions without giving up fairness (compensation would do the trick).

Nevertheless, recent contributions have convincingly argued that the economic ground on which orthodox L\&E is built is fragile. Surely, the explanatory power of this new branch of the social sciences remains considerable. Property-right assignments and violations have important economic consequences on human behaviour. But that does not necessarily justify regulatory or teleological policies.

This article has maintained that evolutionary psychology can further enhance the explanatory power of the L\&E approach by giving operational content to the obvious fact that human beings do not behave like robots. And that their way of thinking plays a crucial role in order to understand behaviour, both individually and collectively. Indeed, human actions reflect not only cost-benefit analyses based on monetary flows, but also 
ideology, emotions and the external stimuli people are confronted with. Hence, 'good law-making' might not always lead to the expected outcome, unless the interaction between the software of the mind and the outside stimuli are properly understood. Thus, problem-solving is no longer a matter of efficiency and optimization, but rather of adaptation.

From an institutional standpoint the evolutionary vision further suggests that there is no such thing as a desirable set of rules (a constitution). The very scope for developing some sort of public-choice-based dynamics of organizations and coalitions seems to be weakened, too ${ }^{34}$; and replaced by the need to develop a theory of interaction between psychological patterns and behavioural routines induced by external constraints that may or may not be accompanied by specific ideologies, belief systems ${ }^{35}$. A potential example is provided by the European Union, a bureaucratic superstate that nevertheless embodies symbols and myths that seem to provide a much longed-for reply to the sense of unsatisfaction felt by many Europeans. In this case predicting the future of the EU institutions requires an understanding of what should be done for the EU to fulfil people's expectations and to what extent and how fast the bureaucratic superstate can alter people's way of thinking, so that they might accept from a federal government a degree of dirigisme which would have been unacceptable at a local level.

\footnotetext{
34 At most, there is room for a theory of political dynamics regarding - say - the nature and evolution of democratic or totalitarian regimes, especially in the presence of tensions between psychological patterns and behavioral routines. And there is also room for studying the dynamics of successful rules - i.e. those that reflect shared behavioral patterns. The ultimate goal is of course to shed light on the agents' way of thinking, the mechanisms that shape the legitimacy of a rule and the acceptance of a norm.

35 Once again, it may be worth reminding that the evolutionary approach may yield different results when applied to culture and to psychological patterns. For cultural traits may change relatively rapidly as a consequence of external constraints. Behavioral routines will reflect these phenomena.
} 
The above does not rule out top-down constitutional engineering and Chicago-style assignments of property rights altogether. Rather, these solutions become a particular case of a general L\&E approach, and apply when the current psychological patterns originate relatively weak spontaneous behavioural routines for lack of references to pre-existing neural frames ${ }^{36}$.

By applying this conceptual framework to the analysis of post-communist countries it has been observed that most postcommunist reformers, including several international agencies, assumed (i) that capitalism would have been built on barren and thus highly receptive ground, and (ii) that free-market reforms were meeting the preferences of most individuals in post-communist countries. It has been argued that those observers were wrong on both accounts. That explains why the assignment of new property rights combined with the creation of a modern legal system - generally dubbed as 'rule of law' made sure that post-communist policy-making ended up in a wide range of different outcomes.

In the end, there seem to exist strong reasons to maintain that 'decision makers should allow free choice of law, as in allowing arbitration in contracts' (Rubin 2005) 37 . The state would not necessarily disappear, but finds its legitimacy in some kind of contract, to which individuals are subject only if they have explicitly accepted it, or at least not opted out of.

36 This follows from the Law of Law's Leverage (Jones 2000, p.2101), whereby rule making is more likely to bring forth expected rational responses, the less the human mind is conditioned by previous experiences or by emotions related to previous experiences.

37 History shows that efficient legal systems are not the outcome of scholarly design, but of competition among legal systems. Indeed, too much faith in scholarly or judiciary design ultimately favors rent-seeking (Zywicki, 2003). 


\section{REFERENCES}

Berkowitz, Daniel, Katharina PIstor, Jean-François Richard (2003), 'Economic development, legality, and the transplant effect', European Economic Review, 47, pp. 163-195. Bernstein, Anita (2005), 'Whatever happened to law and economics?', Maryland Law Review, 64 (101), pp. 101133.

BLock, Walter (1977), 'Coase and Demsetz on private property rights', Journal of Libertarian Studies, 1 (2), pp. 111-115.

Buss, David (2004), Evolutionary Psychology, Boston: Pearson Education.

ElLiCKSON, Robert C. (1991), Order without Law: How Neighbours Settle Disputes, Cambridge: Harvard University Press.

HAYEK, Friedrich A. (1960), The Constitution of Liberty, Chicago: The University of Chicago Press, reprinted in 1978 (paperback edition).

- (1973), Law Legislation and Liberty - Rules and Order, Chicago: The University of Chicago Press, reprinted in 1983 (paperback edition).

Hofstede, Geert (1991), Cultures and Organizations, London: McGraw-Hill International [reprinted in 2003 in London: Profile Books].

Jolls, Christine, Cass Sunstein, Richard Thaler (1998), 'A behavioral approach to law and economics', Stanford Law Review, 50, May, pp. 1471-1550.

JONEs, Owen (2000), 'On the nature of norms: biology, morality and the disruption of order', Michigan Law Review, 98, May, pp. 2072-2103.

Jones, Owen, Timothy Goldsmith (2005), 'Law and behavioural biology', Columbia Law Review, 105, March, pp. 405-502.

Leoni, Bruno (1961), Freedom and the Law, Princeton: D. van Norstrand Co. [reprinted in 1991, Indianapolis: Liberty Fund]. 
Medema, Steven (2005), 'Chicago Law and Economics', in Ross Emmett (ed.), The Elgar Companion to the Chicago School, Cheltenham: Edward Elgar (forthcoming).

Nicita, Antonio, Ugo Pagano (2007), 'Law and Economics in retrospect', in E. Brousseau and J.-M. Glachant (eds.), New Institutional Economics, a Textbook, Cambridge: Cambridge University Press (forthcoming).

NorTh, Douglass (1990), Institutions, Institutional Change, and Economic Performance, Cambridge: Cambridge University Press.

Nussbaum, Martha (1997), 'Flawed foundations: the philosophical critique of (a particular type of) economics', University of Chicago Law Review, 64, pp. 1197-1214.

Opper, Sonja (2005), «New institutional economics and its application on transition and developing economies', in E. Brousseau and J.-M. Glachant (eds.), New Institutional Economics, a Textbook, Cambridge: Cambridge University Press, forthcoming.

PARISI, Francesco, Jonathan KLICK (2003), 'Functional Law and Economics: the search for value-neutral principles of lawmaking', Law and Economics Working Paper Series, 0339, George Mason University.

Pejovich, Steve (1999), «The effects of the interaction of formal and informal institutions on social stability and economic development», Journal of Markets and Morality, 2, 2, pp. 164-181.

RAPACZYNSKI, Andrzej (1996), "The roles of the state and the market in establishing property rights», Journal of Economic Perspectives, 10(2), Spring, pp. 87-103.

Rubin, Paul H. (2005), 'Legal systems as frameworks for market exchanges', in Claude Ménard and Mary Shirley (eds.), Handbook of New Institutional Economics, Dordrecht: Springer, pp. 205-228. 
SAchs, Jeffrey, Wing Thye Woo, Xiaokai YANG (2000), «Economic reforms and constitutional transition», Social Science Research Network Electronic Paper Collection, October.

Schroeder, Jeanne L. (2000), 'Rationality in law and economics scholarship', Oregon Law Review, 79 (spring), pp. 147-252.

SimA, Josef (2004), «Praxeology as Law \& Economics», Journal of Libertarian Studies, 18 (2), Spring, pp. 73-89.

Stigler, George and Gary Becker (1977), 'De Gustibus non est disputandum', American Economic Review, 67 (2), March, pp. 76-90.

ZYWICKI, Todd J. (2003), 'The rise and fall of efficacy in the Common Law: a supply-side analysis', Northwestern University Law Review, 97 (4), pp. 1551-1633. 